\title{
Template for teaching and assessment of problem solving in introductory physics
}

\author{
E. W. Burkholder $\odot,{ }^{1, *}$ J. K. Miles, ${ }^{2}$ T. J. Layden, ${ }^{2}$ K. D. Wang, ${ }^{3}$ \\ A. V. Fritz ${ }^{4}{ }^{4}$ and C. E. Wieman $\oplus^{1,3}$ \\ ${ }^{1}$ Department of Physics, Stanford University, Stanford, California 94305, USA \\ ${ }^{2}$ Office of the Vice Provost for Undergraduate Education, Stanford University, \\ Stanford, California 94305, USA \\ ${ }^{3}$ Graduate School of Education, Stanford University, Stanford, California 94305, USA \\ ${ }^{4}$ Department of Electrical Engineering, Stanford University, Stanford, California 94305, USA
}

(Received 28 October 2019; accepted 13 April 2020; published 24 April 2020)

\begin{abstract}
We introduce a template to (i) scaffold the problem solving process for students in the physics 1 course, and (ii) serve as a generic rubric for measuring how expertlike students are in their problem solving. This template is based on empirical studies of the problem solving practices of expert scientists and engineers, unlike most existing templates which are based on prescriptive, theoretical descriptions of expert problem solving and are largely based on how experts solve textbook-style problems. However, there is still some overlap with existing problem solving templates. In study 1 , we investigated the validity of the template for use in introductory physics in two ways, first, by analyzing the final exam solutions from a Physics 1 course, and second, by analyzing seven think-aloud cognitive interviews as successful introductory physics students worked to solve a challenging problem. The results show that use of the elements of the template is correlated with successful problem solving, the template follows successful students' existing problem solving processes, and explicitly using the template in solving problems does not add additional cognitive load. In study 2, analysis of final exam solutions from a different introductory physics course shows that the relationship between template use and problem solving performance depends on the type and difficulty of the problem. In this work, we also identified some consistent difficulties of unsuccessful students in solving problems which suggests some ways to better teach physics problem solving.
\end{abstract}

DOI: 10.1103/PhysRevPhysEducRes.16.010123

\section{INTRODUCTION}

It is widely accepted that it is essential for students to develop problem solving skills during an undergraduate education in science, technology, engineering, and mathematics (STEM) [1-3]. Indeed, recent graduates of engineering programs cite problem solving as one of the most important skills that they use in their careers [4]. A substantial amount of work in physics education research (PER) has been devoted to characterizing problem solving [5-14], which has provided valuable insight into differences between students and experts in this domain. A number of problem solving guides have since been developed to help students become more expertlike in their problem solving $[15,16]$. For example, Hellers' Competent Problem Solver, which is based on prescriptive theories of expert problem solving [7], has students "visualize the problem,"

\footnotetext{
*eburkhol@stanford.edu
}

Published by the American Physical Society under the terms of the Creative Commons Attribution 4.0 International license. Further distribution of this work must maintain attribution to the author(s) and the published article's title, journal citation, and DOI. "comprehend the problem," use formal concepts and equations to "represent the problem," write a "solution plan," execute that plan, and then "interpret and evaluate the solution." [16]. Many introductory physics textbooks have anecdotally based templates that follow a similar general structure, but may skip certain steps $[17,18]$.

One problem with such guides is that they are often based on procedures followed by experts in solving textbook physics problems, but these are exercises, not authentic problems for the expert physicist. Using such guides is not necessarily helpful to students who lack the experience and expertise necessary to correctly choose and use the proper procedures [19]. Also, such learning transfers poorly to novel contexts [20-22]. We propose, and in this work test, that learning to follow such procedures is much less important than learning to carry out the same cognitive tasks as experts do when they solve authentic problems (such as those in their research). Recent work on problem solving has characterized these cognitive tasks, particularly the decisions experts make, using extensive cognitive task analyses of experts' reflections on their problem solving processes [10-12,23].

The template presented here is based on the work of Price et al. in which they carried out an empirical study 
A. Framing

Visual Representation A basic sketch illustrating what is happening, the important quantities (forces, velocity, weight, energy, etc.), and what you are solving for. (3pts)

Relevant Concepts (2pt)

Similar Problems Previously solved problems with same concepts can provide guidance for solving. (1pt)

Assumptions and Simplifications Any details you are neglecting. (1pt)

Information Needed This includes values given in the problem and values you might need to estimate or look up. (2pts)

B. Planning

Solution Plan (3pts)
C. Execution Carry out your plan for solving. Plug in numbers as very last step. (3pts)
D. Answer Checking

Compare to Estimate (1pt)

Limits Test Look at dependencies (for example, how increasing a variable affects an answer). Equations should make sense in limits (angles 0 and 90 , weight zero or large, ...). (2pts)

Units Check Double check math, units, and use of vectors versus scalars. (1pt) Getting (Un)stuck If you aren’t able to reach a solution, determine where you got stuck for partial credit (you
can consult with peers). $(1 \mathrm{pt})$

Rough Estimate What do you expect the answer to be and why? . (2pts)

FIG. 1. Problem-solving template.

of expert problem solving through an extensive set of interviews of experts in all science and engineering disciplines, including physicists, exploring their problem solving process. This work coded the process in terms of the common set of high-level decisions that they make as they solve authentic problems [23]. Examples of such decisions include how to decompose a problem into more tractable subproblems; what approximations or simplifications are appropriate; and if the solution is reasonable. Underlying this decision making is an expert predictive framework-a mental model of a problem's key features and the relationships between them-which allows the expert to explain observations and make predictions. Predictive frameworks are similar to other theoretical constructs in expertise and problem solving, such as schemata or mental models, and are characterized by three central features. First, a predictive framework allows the expert to identify key features of the problem and eliminate unimportant elements. Second, it allows the expert to explain the relationships between these key features, which includes a degree of mechanistic reasoning about the relationships between variables. Third, the predictive framework is sufficiently detailed that it allows experts to conduct mental simulations of experiments by manipulating various problem parameters.

Based on this empirical cognitive task analysis of expert decision making, we developed a solution template for students to use as they solved problems in some of the introductory physics courses offered at Stanford (Fig. 1).
This approach is well aligned with the cognitive apprenticeship model, in which the expert cognitive process of problem solving is made visible to students through modeling, scaffolding, and coaching [19,24]. The aims for this template were twofold. First, we hoped that this template would scaffold expert decision making for students, and thus help them become better problem solvers, similar to van Heuvelen's active learning problem sheets and the work of Holmes et al. [25-27]. Second, we hypothesized that the template could be used to better measure students' problem solving practices as they solved introductory physics problems by providing more detail as to their process than offered by the typical student solution.

\section{BACKGROUND}

The research underlying the problem solving template distinguishes itself from prior research in problem solving in several ways [23]. First and foremost, our list of decisions represents the decisions made by experts as they solve authentic problems in their work, rather than solving textbook problems. Indeed, it is acknowledged in much of the problem solving literature that a problem is a task where the path toward the goal is uncertain. Yet, much of the empirical work on how experts solve physics problems, particularly the comparisons of experts and novices, has relied on expert solutions to textbook problems, where the experts frequently do know the path toward the goal as soon as they see the problem. Thus, the procedures followed by 
TABLE I. Correspondence between categories of decision making identified by Price et al., specific expert decisions falling into those categories, and relevant steps in the template.

\begin{tabular}{|c|c|c|}
\hline Category of decisions & Example decisions & Template steps \\
\hline Goals and criteria & - Decide what the goals for this problem are & N/A \\
\hline Problem framing & $\begin{array}{l}\text { - Decide what are important underlying features } \\
\text { - Decide which predictive frameworks are relevant } \\
\text { - Decide what information is relevant/important } \\
\text { - Decide what are related problems seen before } \\
\text { - Decide how predictive frameworks need to be modified to fit this situation }\end{array}$ & $\begin{array}{l}\text { - Visual representation } \\
\text { - Relevant concepts } \\
\text { - Similar problems } \\
\text { - Assumptions and } \\
\text { simplifications } \\
\text { - Information needed }\end{array}$ \\
\hline Solution planning & $\begin{array}{l}\text { - Decide how to decompose problem into more tractable sub-problems } \\
\text { - Decide what to prioritize } \\
\text { - Decide what information is needed to solve the problem } \\
\text { - Decide on specific plan for getting additional info. }\end{array}$ & $\begin{array}{l}\text { - Solution plan } \\
\text { - Rough estimate }\end{array}$ \\
\hline Analyze information & $\begin{array}{l}\text { - Decide what calculations are needed } \\
\text { - Decide whether information coming in matches expectations }\end{array}$ & $\begin{array}{l}\text { - Execution } \\
\text { - Compare to estimate }\end{array}$ \\
\hline Evaluate solution & $\begin{array}{l}\text { - Decide whether assumptions still make sense } \\
\text { - Decide whether additional information is needed } \\
\text { - Decide how well the solution holds }\end{array}$ & $\begin{array}{l}\text { - Check limits } \\
\text { - Check units } \\
\text { - Getting unstuck }\end{array}$ \\
\hline
\end{tabular}

experts in solving these exercises will not represent their approach to a task that constitutes a true problem for them. Second, most existing problem solving templates are formulated as a set of procedures rather than decision processes. These procedures do not transfer well [20-22], but we propose that learning the underlying decision processes will lead to improved transfer. Third, our list of decisions represents a complete account of how experts solve these authentic problems-the typical textbook problem is designed to remove many of those decisions (appropriate simplifications and approximations, etc.). Some previous research qualitatively describes the strategies and approaches experts use but does not provide a detailed list of all the cognitive steps used by experts. Finally, an interesting but not central feature to this work is that we believe this list of decisions is not specific to physics. As will be discussed in future publications, we believe this set of decisions provides a general framework for problem solving that can be applied in any scientific discipline.

Each step in the problem solving template (Fig. 1) reflects a decision cited by experts as important to their problem solving process. This template prompts students to "frame the problem" (draw a visual representation, think about similar problems that they have solved before, list the relevant concepts and assumptions, list the information needed to solve the problem) then "write a solution plan," and execute that plan. The execution step corresponds to the only part that is typically required and graded for exam problems in most Physics 1 courses. Finally, students are prompted to check their answer (check units, compare to estimates, and check limiting cases) or determine where they got stuck if they were unable to reach a solution. While this list of decisions is not exhaustive (there are about 30 total decisions in Price et al.'s study), it covers the most important components of experts' problem solving strategies. We show the correspondence between the categories of decisions identified by Price et al. and the steps in the template in Table I.

The template shares many similarities with the problem solving process outlined by Heller and Heller, and some similarities with van Heuvelen's problem solving sheets [15]. Heller and Heller's Competent Problem Solver outlines a five-step strategy based mostly on Heller and Reif's prescriptive model of physics problem solving $[7,16]$. This model of problem solving is theoretical and not based on the actual problem solving processes of experts, unlike the model we develop here. Despite the lack of an empirical basis for this model, it shares many similarities with ours. Their first two steps, focusing the problem and describing the physics, is similar to what we call problem framing. However, their template does not prompt students to think about the assumptions and simplifications they are making. This highlights the difference between textbook physics problems, where the assumptions are often stated explicitly for the students, and real problems where the assumptions and simplifications have to be decided upon by the solver. 
For example, students are often prompted to draw free body diagrams for a problem, which is a well-defined procedure students learn to execute, but which does not always translate to successful problem solving [28]. In contrast, we prompt students to draw generic graphical representations (which requires them to make simplifications to the physical scenario described), the goal of which is to carry out the particular cognitive task of providing a useful visual representation for solving the problem, rather than matching a particular procedure.

Heller and Heller prompt students to check that their work is reasonable, as do we, but this is quite difficult for novices to do, as it encompasses multiple cognitive tasks. In our template, we decompose answer checking into multiple steps, beginning with the task of first making an estimate of the result to establish a basis for their evaluating their answer later on. We also explicitly prompt students to check dependencies of expressions on certain variables, limiting cases, and units. Importantly, these steps force students to formulate a predictive framework, a critical initial step in the problem solving process of experts. Finally, our template also includes a way for students to receive partial credit for carrying out important cognitive steps, even if they are unable to reach a final solution. This makes the template a valuable learning tool, as it encourages students to reflect on the decisions that they make, and provides feedback on that reflection, rather than only focusing on the final solution. Van Heuvelen's problem solving sheets follow a similar procedure, but they constrain the decision space to a degree that limits the applicability of the template. For example, a pictorial representation is drawn for them and students are only asked to draw a coordinate axis and label important symbols.

Problem-solving templates are also commonly presented in introductory physics textbooks $[17,18]$, however these are also prescriptive and largely based on how the authors and instructors solve the textbook exercises. While these textbook templates have a number of elements that overlap our empirically based template, they overlook many practices critical for solving authentic problems. For example, Young and Freedman [17] outline a problem solving approach that asks students to identify the relevant concepts, choosing equations and deciding how those equations will be used, then execute the problem, and evaluate the solution. Knight's problem solving process asks students to "model" the problem and "visualize the problem," before solving and assessing the solution [18]. There are counterparts to each of these steps in our template, but both of these largely neglect identifying important assumptions (those are almost always explicitly given in textbook problems, although not in the real world), or think about similar problems that students have solved before. Most importantly, they give far less weight to the framing and planning steps and their articulation than does our template, as well as does the actual problem solving process of expert scientists and engineers.
Our motivation for introducing this template is to give students the opportunity for deliberate practice in problem solving, an essential step in developing expertise [29]. Furthermore, there is a substantial amount of work in PER showing that pieces of the problem solving process we scaffold with the template are useful educational tools. For example, Leonard et al. showed that having students develop strategies (i.e., identifying relevant concepts and planning a solution) and modeling these strategies for students in lecture resulted in increased understanding of basic physics principles and how they are used in solving problems [30]. Similarly, Dufresne et al. and Mestre et al. showed that having students follow an expertlike problem solving procedure helps students focus on the deep structure of problems and can improve novice's ability to solve problems [31,32]. Warren showed that having students practice evaluating their solutions (a step shared in our template and Heller and Heller's) can also lead to improved problem solving performance [33].

A further motivation for developing the template was to have a rubric with which we could evaluate how well students were learning to solve problems. Each step in the template is assigned a point value that roughly represents our estimate of how important each step is in the problem solving process. For example, planning and execution are weighted equally because experts are observed to spend as much or more time planning their solution than they do actually executing the solution. Similarly, visual representations are weighted heavily because experts use such representations frequently when solving problems [5,34]. Docktor et al. developed a rubric to assess problem solving that is general, but does not directly score students on how well they make the decisions associated with successful problem solving [35]. Rather, it focuses on five general criteria that are important in problem solving. We argue that grading students on how well they make the individual expert decisions provides more useful feedback for the instructor, as it identifies a very specific decision students must practice making. Following the suggestion of Hull et al., we use the template as a guide for problem solving rubrics, but adapt each rubric to the problem at hand (see Appendix) [36]. That is, the criteria for what constitutes a good solution plan, for example, will depend on the problem, though writing a complete, detailed plan is an important part of solving any problem.

\section{STUDY 1}

The research question addressed by the first study is, "Does the template, which is a simplified adaptation of the problem solving framework used by scientists in solving authentic problems, accurately reflect the problem solving processes used by successful introductory physics students when solving introductory physics course problems?" 
3. (12 points, one part) Atwood machine

An Atwood machine is composed of two masses, $m_{1}$ and $m_{2}$, connected by a massless

rope over a pulley with a moment of inertia $I$ and radius $r$. Suppose that $m_{2}$ is

larger than $m_{1}$, what is the the acceleration of $m_{1}$ ?

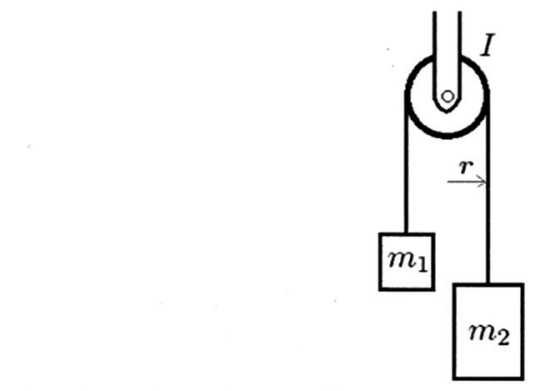

(a) Atwood machine problem

\begin{abstract}
Zeus the miniature schnauzer (who is the size of a large housecat) has figured out how to get over a baby gate designed to keep him confined to the bedroom during the work day. The gate is 3 feet high and the distance between the doorway and the back wall is about 10 feet. Do you think he is jumping over the gate, or has he found a way to climb over it?. Include descriptions of quantities you would need to measure or estimate and justify them.
\end{abstract}

(b) Jumping dog problem

FIG. 2. (a) The Atwood machine problem from the 2018 final exam in Physics 41, and (b) the jumping dog problem from the thinkaloud interviews conducted in 2019.

\section{A. Methods}

Data were collected from Physics 41, the standard calculus-based introductory mechanics course at Stanford, in the winter quarter of 2018. The course closely adhered to the treatment of introductory mechanics in Young and Freedman [17], covering force and torque, Newton's laws, conservation of energy, conservation of momentum, uniform circular motion, and conservation of angular momentum. The instruction in Physics 41 was largely traditional, consisting mainly of lectures with limited use of clicker questions and Peer Instruction [37] and weekly recitation sections primarily using problems from Tutorials in Introductory Physics [38].

The data consisted principally of final exam scores of 115 students, as well as those students' written solutions to the Atwood machine problem [Fig. 2(a)] on the final exam. 76 of these students were enrolled in a one-unit companion course designed to provide extra support for students without a strong physics background. These students practiced using the problem solving template in weekly problem solving sessions outside of lectures. The remaining 39 students in the sample were selected from the remaining 442 enrolled in the course such that their final exam grades were statistically indistinguishable from the students in the companion course (using a $t$ test to distinguish), but these 39 students did not have prior experience using the template. We initially selected $10 \%$ of the remaining students (44), but discarded scores from students for whom we did not have complete background data (FMCE pre- and postscores). The Atwood machine problem required students to use Newton's second law with both forces and torques to find the acceleration of a mass attached to a second mass by a massless rope over a pulley with finite mass. Students were not prompted to follow the template during the final exam. The third and fourth authors coded students' solutions for how closely students followed the problem solving template; they reached an interrater agreement of $80 \%$, and then discussed and resolved all disagreements. Students were assigned a "Template Use Score" which reflects how closely students' solutions followed the problem solving template (e.g., evidence of solution planning, drawing visual representations). We call students' TA-assigned grades on the Atwood machine problem their "Execution Scores," which reflect how accurate their solutions were, as judged by the TAs when grading the final exam.

In addition to the quantitative analysis described above, we conducted 7 interviews with students who successfully completed the standard (Physics $41, N=5$ ) and honors (Physics 61, $N=2$ ) introductory mechanics courses in 2019. During each interview, the students were asked to solve a physics problem [Fig. 2(b)] using a modified version of the problem solving template and think aloud while doing so. The problem asked them to evaluate whether a small dog was able to jump over a gate, or whether it seemed more likely that the dog had found a way to climb the gate. This was not a typical textbook problem; it was a "real-world" problem that required students to make decisions about what the important features of the problem were, and what simplifications and approximations they could 
make to come to an answer. It required students to make estimates and reason whether their thinking was correct using physical intuition. One student arrived at an acceptable answer, while the other six students failed to do so within $60 \mathrm{~min}$. One of these six students arrived at an answer, but their answer was not supported by sound physical reasoning. Another one of the six students got stuck on deciding the details of how to model the dog (point mass versus extended object), and did not finish within $60 \mathrm{~min}$. The remaining four students made some progress toward a correct solution but got stuck when attempting to model how the dog leaves the ground or in determining the velocity with which the dog must leave the ground. These students declared that they were stuck and did not attempt to proceed further.

The interviews were transcribed by the second author and then coded using Price et al.'s cognitive task analysis of expert problem solving [23]. The interviews were coded collaboratively by the first and second authors with $99 \%$ agreement. We analyzed the types of decisions the students made (e.g., ones related to solution framing, planning, information gathering, etc.) and recorded the frequency of these decisions. We also coded instances when students were making expert problem solving decisions without being prompted to do so by the template, as well as instances when the students were confused by the template prompts.

\section{B. Results}

Analysis of exam solutions.-For the Atwood machine problem, we found a strong correlation between the template use score and the execution score students received $(r=0.73, p<0.001)$. Furthermore, there was a strong correlation between this template use score and overall final exam grade for students in Physics 41 $(r=0.63, p<0.001)$. This was particularly notable as about half of the exam was comprised of short-answer questions with a substantial conceptual component. These correlations suggest that the template reflects the problem solving practices of successful introductory students (see Fig. 3). The correlations were of similar magnitude for the students who were in the companion course and those who were not, indicating that the problem solving template has some validity even when used solely as a post hoc measurement tool.

Analysis of think-aloud interviews. - In each interview, we coded an average of 31 instances of where students made one of the expert decisions identified by Price et al. [23]. We plot the average number of expert decisions made by students during the think-aloud interviews in Fig. 4 . Many types of decisions, e.g., deciding on simplifications and assumptions, were made multiple times throughout each interview. All of the decisions made by the students fell into one of five categories defined by Price et al. (deciding on goals and criteria for the solution, framing the problem, planning the solution, analyzing information, and evaluating the solution).

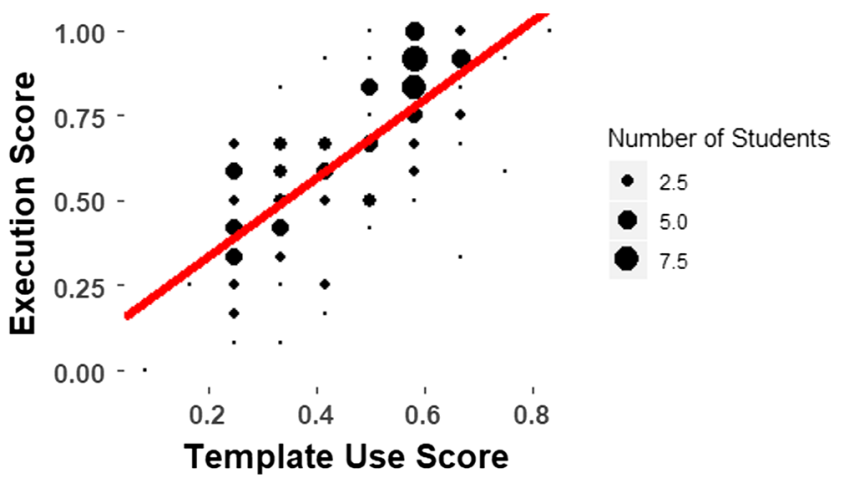

FIG. 3. Scatter plot of execution scores (TA-assigned grades) versus template use scores (how closely students followed the problem solving template) for the Atwood machine problem. The red line is the ordinary least squares linear fit to the data.

In the interviews, each student made an average of 13 decisions related to the framing of the problem, which included selecting a predictive frameworks (e.g., 2D motion), usually by taking a framework they had used for other physics problems and attempting to adapt it to the problem at hand. All students made some decisions regarding their solution plan, particularly with respect to pieces of information they would need to collect and assumptions or simplifications they would need to make to reach a solution. The one student who reached a correct solution made nearly twice as many decisions than the other students regarding a plan for collecting information needed, which aspects of the problem were most important to focus on, and how to use the collected information to reach a solution:

"So first $1 / 2$... or actually, no. I would want to use that equation... (mumbles) Ok so I guess I would, because I

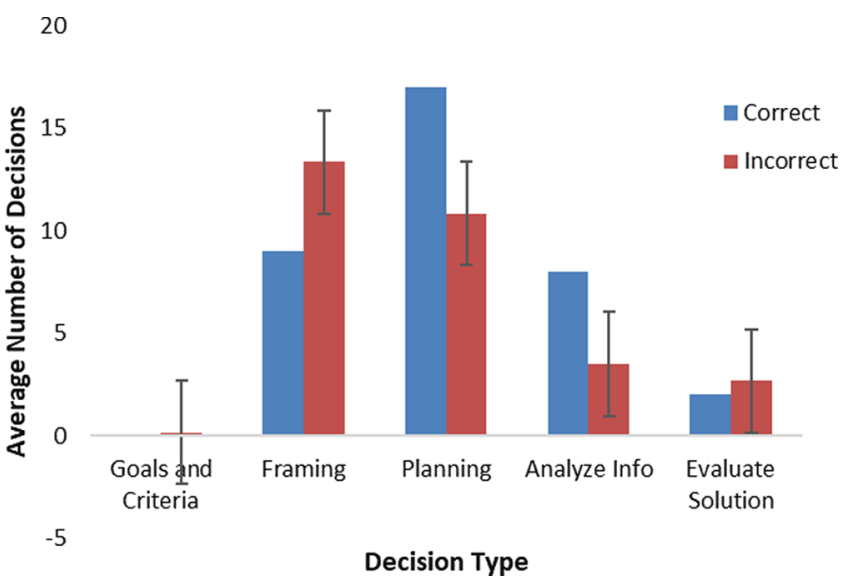

FIG. 4. Average number of decisions made in problem solving think-aloud interviews by students who got the correct answer (blue) and did not (red). Decisions were aggregated into five of the categories outlined in Ref. [23]. Error bars on the incorrect bars represent standard deviations in the number of decisions made. 
don't have a time component, I would want to use an equation that's something like the velocity final squared equals the initial velocity plus 2 times, like acceleration and distance. Something like that, I don't know if that's right. But, so then I would... in order to solve for how much vertical velocity I would have to have, I would set the final velocity to 0, because that's when the dog would reach the height it would have to achieve in order to jump the fence. "-Ben (pseudonyms are used throughout this paper).

Even though Ben is not completely confident, he has decided that he is comfortable proceeding and gathering relevant information (vertical velocity when the dog leaves the ground). Notably, his plan for gathering information is specific and involves equations, which are key features of any expert plan for solving authentic physics problems.

During the interviews, 5 of the 7 students followed the problem solving template without being reminded by the interviewers. One of the $5 \mathrm{did}$ ask for clarification as to what he should write for relevant concepts, but there were otherwise no instances where students showed any uncertainty with the interpretation of the template prompts. Another one of the 5 cited the template-in particular, the prompt to write a solution plan-as the reason he got stuck. However, he showed no indication of misunderstanding the prompt, and getting stuck when writing a solution plan was a consistent marker of students who were not able to successfully solve the problem. None of the students expressed feelings that the template was forcing them to go through an inauthentic process to solve the problem. This preliminary analysis gives us some confidence that the template can be used to measure the problem solving practices of successful introductory students.

\section{Discussion}

For the Atwood machine problem, we found a strong correlation between template use scores and problem execution scores, as well as final exam grades. This indicates that the dimensions of problem solving measured by the template are reflective of the problem solving practices of successful introductory students.

Furthermore, in the problem solving interviews we found that students employed most of the expert problem solving decisions that the template measures. We found no examples of decisions that were not identified by Price et al., only failures to make some of those decisions. About $40 \%$ of the decisions made were related to framing the problem - selecting relevant predictive frameworks, creating abstract representations of the problem, and generating potential solutions. Students who were unsuccessful spent more time framing the problem because they do not have a readily accessible predictive framework. Solution planning always involved making assumptions and simplifications, decomposing the problem, and deciding what information was needed to solve the problem. The successful student we interviewed made nearly twice as many decisions related to solution planning compared to the six students who were unable to solve the problem presented in the interview. He made decisions about specific plans for gathering relevant information and prioritizing what information to collect. This is consistent with other work examining expert-novice differences, where experts exhibit far more planning [39].

The interviews also provide detailed insight as to where the difficulties lie for students in learning to solve problems. All observed difficulties can be tied back to weaknesses in students' predictive frameworks. This also appeared to be the dominant difficulty in the exam solutions we coded. Students in the interview group encountered several different types of difficulties with formulating a suitable predictive framework. One of the unsuccessful interview students, Gerhard, had difficulty adapting his predictive framework for projectile motion to the problem at hand.

"Have you previously solved problems with the same concepts? Yes, but no. I don't know, it seems like I'm not sure if I can model the dog here as just a point in space, or (mumbles). So, similar problems would be like throwing up a ball solving for these (mumbles). I would say that this problem is more confusing textually, just because I'm not sure if that's the right way to model the problem, and (stares at sheet)."-Gerhard.

In the above excerpt, Gerhard attempts to reflect on similar problems he has solved (at the prompting of the template). He fails to do so because he is trying to search for an exact match to the problem's surface features-an animal jumping over a barrier. This is in line with the results of Chi et al. [6]. He does recognize that kinematics is the relevant predictive framework he wants to use to solve the problem, but he is unsure how to adapt that framework to this particular scenario.

Another student, Isaac, was able to adapt his predictive framework for kinematics and 2D motion to fit the problem, but he struggled with identifying the most important features of the problem he would need to attend to in order to reach a solution:

"Ok, so, so I used kinematics to find the maximum jump height, and then I would see, ok, so obviously the max... if the maximum jump height is less than 3 feet, then there's no way it can possibly clear the gate while jumping. So, if less than 3 feet, can't jump over. Ok and if it's greater than 3 feet, then we need to figure out, ok, so, if it's greater than 3 feet, it means it can jump over and there's a small window of time, um, in which, you know, theoretically, like if it was going fast enough it could clear the gate. You know, if it's much greater than 
3 feet, that means that, um, you know, it could, it could, it could jump starting pretty far back without going too fast and it would still be able to clear the gate, because, um, you know, it would be like high enough that even with moving slowly the dog would be able to, you know, stay above 3 feet for long enough. But...um...but... yeah, right. So what I would do then is, I guess, um, ok, so, so, so the, so the dog would be travelling at an initial speed. So I'm gonna assume, I guess that the dog is starting from the full 10 feet back, because that would give us the big...because the faster the inti the running speed...that'd be...I guess that... yeah... also the faster running ...the... the speed it's running before it jumps, the better chance it has of getting over the gate because... hmm not necessarily though. Let's just go with that for now."-Isaac.

Isaac identifies the jump height as important, but then struggles to sort out whether it matters that the dog has a running start, or whether it matters how long the dog is in the air. Isaac goes back and forth between various aspects of the problem, and never reaches a definitive conclusion during the interview. As a result, he also struggles with a plan for gathering the pieces of information that he thinks will be important:

"Again, I don't know why that information would be... but I feel like that's the only way to get a real clear picture of, it this would be possible. I feel like we would easily be able to find the top speed of a dog like this, but it seems less likely to me that there would be, um, information available about how fast it takes for a dog to achieve its top speed."-Isaac.

Paul is another example of a student that failed to formulate a plan to gather relevant information:

"And I guess information I need like something like the weight of the dog would be helpful so dog's weight. How much... how high can he jump. How high can he jump. Um how fast he can run. Some variables like those and I guess a solution plan right there (points to drawings)."-Paul.

Notably, Paul interpreted his visual representation of the problem as representing a sufficient plan, even though it did not contain any relevant equations, quantities he would solve for, or evidence of problem decomposition.

In the above excerpts, failure to solve the problem can be traced back to a failure to correctly make two expert decisions. The first was a failure to reflect on how certain predictive frameworks need to be modified to meet a specific problem context. Students could choose a relevant predictive framework (that one could indeed use to solve the problem) but were unable to see how precisely that framework could be used to solve the problem at hand. This is a weakness in problem framing. The second failure was an inability to decide on a specific plan for solving the problem. We note that it is not surprising that students who were otherwise successful in introductory physics were largely unable to solve the problem in Fig. 2(b). This problem requires students to decide on estimates of physical quantities and simplifications or assumptions. In typical introductory physics problems, all of these decisions are made for the students, so even successful students are not able to practice authentic decision making (problem solving).

The answer to our research question is yes: the template accurately reflects the problem solving practices of introductory physics students solving introductory level problems. From the cognitive think-aloud interviews it appears that solution planning may be a more likely failure mode of problem solving than other aspects of problem solving measured by the template. This suggests a more nuanced relationship between template use and problem solving success that we investigate further in Study 2.

\section{STUDY 2}

Based on the findings in the previous study, our research question for study 2 was, "What are some important variables that determine how useful the template is in predicting problem solving success?"

\section{A. Methods}

Data were collected from Physics 41E, the introductory calculus-based mechanics course for students with less high school physics background than most Physics 41 students. Physics 41E covers much of the same material as Physics 41. Physics 41E was taught using interactive engagement strategies, primarily consisting of cooperative group learning through in-class activities regularly interspersed with clicker questions. These students practiced solving problems using the template on weekly homework assignments and in weekly problem solving sessions throughout the quarter. Most of the homework problems and exam problems in Physics 41E were graded according to students' use of the template, and the students were aware of this in advance (these problems were clearly labeled).

The data consisted of student solutions to two problems from the 41E final exam (see Fig. 5):

- Horsepower problem: This problem invokes knowledge of the work-energy theorem and the definition of angular velocity to derive the unit conversion from watts to horsepower [Fig. 5(a)]. Student solutions to this problem were written on the template.

- Truck problem: In this problem, students use conservation of energy or kinematics to find the maximum height a runaway truck will coast up a rough 
6. Engine power is sometimes expressed in terms of "horsepower." One horsepower was defined by James Watt, who observed that a horse could turn a particular mill wheel with a radius of $3.7 \mathrm{~m}$ at a constant rate of 144 times per hour by exerting a force of $81.6 \mathrm{~kg}$ tangentially to the wheel. What is the conversion for horsepower to kilowatts?

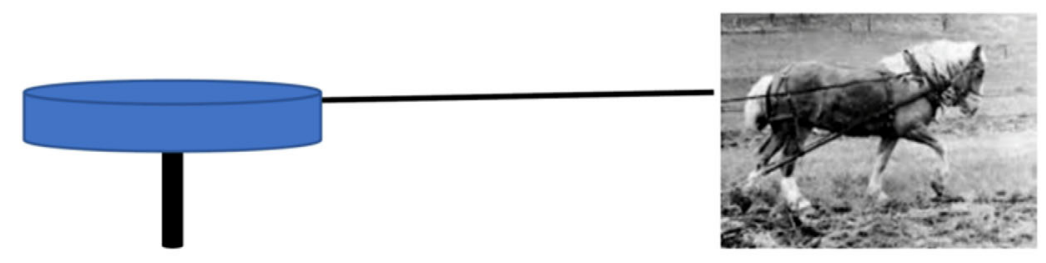

(a) Horsepower problem

3. A truck of mass $M$ is driving down a steep mountain road at a speed $V_{0}$, and suddenly its brakes fail. It coasts without friction a distance $d$ down the slope before getting to a runaway truck ramp. How fast is it going when it gets to the ramp?

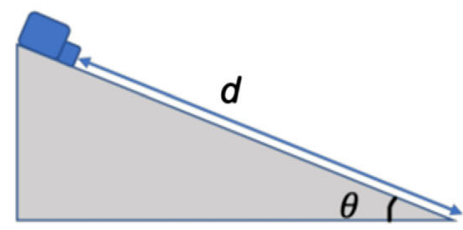

8. A truck of mass $M$ has lost its brakes and is going a speed $V_{\text {in }}$ when it gets to a runaway truck ramp. The ramp is made of soft sand and angled uphill at an angle $\phi$. The truck slows down by sliding through the sand which provides a coefficient of friction $\mu$. How far a distance up the ramp will the truck slide before coming to a stop? Leave your answer in terms of algebraic quantities, Vin, $\phi$, etc.

(b) Truck problem

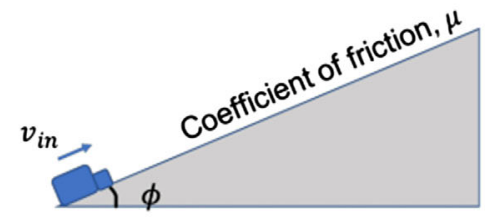

FIG. 5. Horsepower problem (a) and truck problem (b) from the Physics 41E final exam.

surface before coming to a stop [Fig. 5(b)]. On the Physics 41E final exam, this was split into two parts, and students wrote their solutions on the template for the second part only.

We coded solutions to the horsepower and truck problems for 50 students from Physics 41E using the problem solving template we used for the interviews in Study 1 (the specific rubrics may be found in Appendix). These 50 students were all students for whom we had course data and FMCE pre- and postscores. As in Study 1, students were given a template use score based on how closely their solutions followed the template; we divided the template use score into a framing score and a planning score. The framing score encompassed drawing a visual representation, listing relevant concepts, making assumptions and simplifications, and specifying what information is needed to solve the problem. The planning score measured how detailed, specific, and complete students' plans for solving the problem were. The truck and horsepower problems were coded by the second author, and a sample of the solutions were coded by the first author to check interrater reliability. Only one systematic difference was noted between the two coders, and it was resolved. As in the previous study, students were also given an execution score according to how accurate their solutions were.

The data were analyzed using multiple linear regression, which tests a hypothesized linear relationship between the outcome variable (execution score) and predictors (solution planning, solution framing). The quality of the regression models was determined by the significance of the regression coefficients, as well as the adjusted $R$-squared value for the model, which is the fraction of the variance in the outcome explained by the variance in the predictive variables.

\section{B. Results}

We used regression analysis to model the relationship between execution score (the accuracy of the solution) and 
TABLE II. Multiple regression analysis of execution score on framing score and planning score for the three exam problems. Coefficients represent the fractional change in execution score per one-point change in planning or framing score. $* * * p<0.001$, $* * p<0.01, * p<0.05$.

\begin{tabular}{lcc}
\hline \hline & Horsepower & Truck \\
\hline Intercept & $0.067(0.11)$ & $0.54 * *(0.080)$ \\
Problem framing & $0.040(0.040)$ & $0.13(0.28)$ \\
Solution plan & $0.73 * *(0.11)$ & $0.0087(0.27)$ \\
Adjusted $R^{2}$ & 0.47 & -0.038 \\
\hline \hline
\end{tabular}

problem framing score and solution planning score (template use) on the horsepower problem and the truck problem. The results of this analysis may be found in Table II. We scaled all scores to be out of one point for ease of interpretation.

Horsepower problem.-The solution planning and framing scores explained $47 \%$ of the variance in execution scores for the horsepower problem, with the planning being the dominant contribution. For every one-point increase in framing score, there was a $b_{f}=0.040 \pm 0.040$ point increase in execution score and for every one-point increase in solution planning score, there was a $b_{p}=0.73 \pm 0.11$ point increase in the execution score. The correlation between planning and execution is large, 0.73 $(p<0.001)$, but the correlation between framing and execution is not statistically significant.

Truck problem.-The solution planning and framing scores explained none of the variation in execution scores for the truck problem. Neither planning $\left(b_{p}=0.0087 \pm 0.27\right)$ nor framing $\left(b_{f}=0.13 \pm 0.28\right)$ was a significant predictor of execution score (how accurate students' solutions were). We found the lack of correlation curious, so we looked more carefully at the individual solutions for the truck problem. Several patterns emerged. (i) Most students $(N=37)$ attempted to use kinematics instead of conservation of energy to solve the truck problem. While this was straightforward for the first part of the problem, calculating the correct acceleration for the second part was difficult (21 students got this wrong). Very few students recognized that the deceleration of the truck would have contributions from both gravity and friction. (ii) More generally, there was difficulty incorporating frictional losses into the problem. Students often made mistakes in calculating the resistive force due to friction $(N=12)$, and/or in computing energy dissipated by the frictional force $(N=14)$. (iii) Many students neglected terms in the energy balance $(N=10)$, such as the initial kinetic energy of the truck (in part 1) or the gravitational potential energy of the truck when it had come to a stop. (iv) A number of students $(N=12)$ actually framed the problem in terms of conservation of energy, but then attempted to solve the problem using kinematics.

\section{Discussion}

These data reveal that the relationship between template use and problem solving success is more complex than previously indicated. On the horsepower problem, the solution planning score was found to be an important predictor of execution score, while problem framing was not. There was a conspicuous absence of a correlation between both solution planning and problem framing scores and execution scores for the truck problem.

We expect that the relationship between problem framing and solution accuracy depends on the content knowledge required to solve the problem in relation to the prior knowledge possessed by the students $[5,6,39]$. The horsepower problem was very simple - it required the use of two straightforward formulas to compute a unit conversion. We hypothesize that some students saw this problem as too simple to require deliberate framing, and thus did not put much effort into writing out their framing when prompted to on the exam. In fact, about $10 \%$ of the students had a framing score of less than $30 \%$, but an execution score of greater than $67 \%$. The problem had two steps, so some planning was still evident in successful students' solutions. The Atwood machine problem in Study 1 was very challenging and required a substantial amount of content knowledge-analysis of forces and torques in a multibody system. We posit that students were unable to succeed unless they carefully framed the problem to organize all the relevant content required. Furthermore, it was split into three parts, each requiring a different force-torque balance, so substantial planning was required. Indeed, for the Atwood machine problem, we found that execution score was strongly correlated with solution planning, $b_{1}=0.60 \pm 0.084$, and problem-framing, $b_{2}=0.30 \pm 0.088$ (both correlations are significant at the $p=0.001$ level).

The lack of correlation on the truck problem was likely due to the relative complexity of the problem compared to the students' level of mastery. They possessed most of the necessary content knowledge (e.g., formulas for potential and kinetic energy, the work-energy theorem, kinematics equations, etc.), but their predictive frameworks were not strong enough for them to be able to adequately apply them to the context and thereby plan and execute solutions. Indeed, the lack of correlation between solution planning and execution seems to be due to a floor effect in solution plans -38 of the 50 students did not even present a complete plan, let alone a detailed one, and so received a planning score of less than $33 \%$. We hypothesize that the lack of correlation between framing and execution reflects students' inability to organize their relevant content knowledge in a way that would allow them to solve the problem.

The issues noted in the truck problem solutions can be tied to weaknesses in students' predictive frameworks. 
First, solving this problem with kinematics is far more difficult than with conservation of energy. This suggests difficulties in selecting appropriate predictive frameworks. Second, students had substantial difficulties adapting their kinematics predictive frameworks to the problem, because of the complexity of the context. This is evidenced by the difficulty appropriately incorporating friction, neglecting other relevant terms into the energy balance or the expression for the truck's deceleration. Framing the problem in terms of conservation of energy and then solving it with kinematics indicates a breakdown at the planning stage. Students framed the problem in terms of conservation of energy, but did not have a sufficiently robust understanding of how to incorporate all the relevant energy terms to decide upon a detailed solution plan.

Our observations for answering these research questions thus suggest that teaching of introductory physics problem solving should focus on students' development and application of predictive frameworks. This stands in contrast to many existing methods, which focus on teaching problem solving procedures. Indeed, our own attempts to teach problem solving in Physics 41E fell into the same trap. We hypothesized that repeated practice making some of the expert decisions, scaffolded by the template, would be the most effective way to help students improve their problem solving skills.

Analysis of homework assignments in Physics 41E from weeks 2 and 8 of the quarter for 8 students (Fig. 6 and Table III) suggest that this was not correct. We used the template to score students on problem framing, solution planning and solution execution for one homework problem from each of weeks 2 and 8 of the winter quarter in 2019. These were real-world physics problems written by the first author. The solutions of the students who received the three lowest final exam scores and the

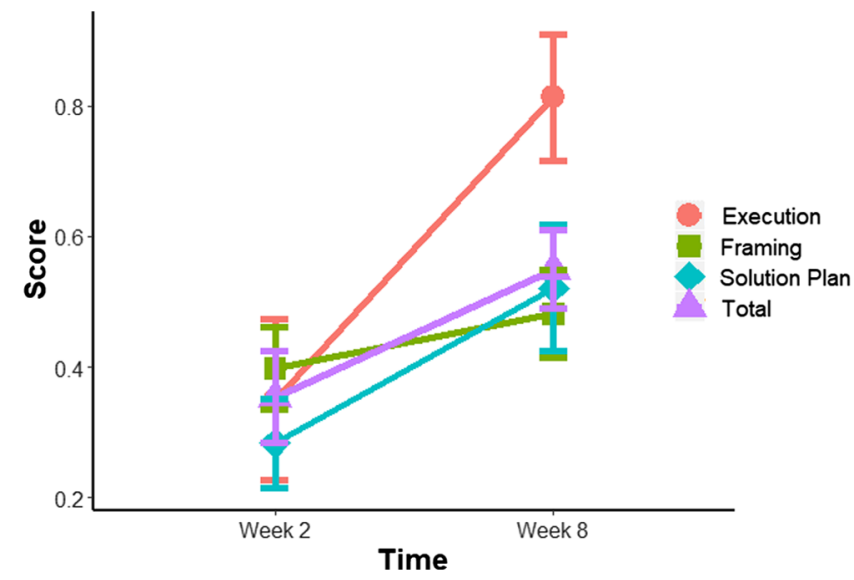

FIG. 6. Scores on execution (circle), framing (square), planning (diamond), and total (triangle) scores on homework problems from week 2 and week 8 for 8 students in Physics 41. Error bars represent standard errors.
TABLE III. Change in framing, execution, planning, and total score on homework problem from week 2 to week 8 . $* * * p<0.001, * * p<0.01, * p<0.05$.

\begin{tabular}{lc}
\hline \hline Category & Change in score \\
\hline Framing & $0.081(0.057)$ \\
Solution plan & $0.24 *(0.092)$ \\
Execution & $0.45^{* *}(0.14)$ \\
Total & $0.19 *(0.065)$ \\
\hline \hline
\end{tabular}

five highest exam scores were coded by the second author. The scoring rubrics are also given in Appendix. The students improved in their solution framing, planning, and execution over time, but only the increases in execution score $(45 \pm 14 \%)$ and planning score $(24 \pm 9.2 \%)$ were significant. The changes were not significantly different for the top-performing or bottomperforming students. We note that, though solution planning improved, both solution planning and problem framing were substantially lacking on student homework assignments (scores averaged $\sim 50 \%$ in week 8). Clearly, this improvement was insufficient to allow them to be successful in solving the truck problem. They had learned the procedure of expert problem solving, but not the predictive frameworks they needed to actually solve more complex physics problems.

\section{GENERAL DISCUSSION AND CONCLUSIONS}

We studied if the problem solving template based on the decision-making processes of experts is a useful measure and scaffold of problem solving by introductory physics students on introductory problems. The data suggest that it is, but there are caveats to its utility. Namely, problems must be appropriately designed in order for the students to employ problem solving processes that mirror those of experts (and thus that will be measured by the template). When problems are appropriately complex, there is a strong correlation between how closely students follow the template and their grade on the problem. If problems are too easy or too hard, use of the template no longer consistently correlates with student's scores on the problem.

This suggests a few criteria that must be met if the problem solving template is to be an effective scaffold to solving and meaningful measure of students problem solving practices. First, the problem must be sufficiently complex that it requires students to make some of the expert decisions identified by Price et al. during the solution process. That is not to say that it should require more content knowledge or the use of specific "tricks" to arrive at a solution. Rather it should require students to, for example, use (and perhaps gather) a sufficient amount of information to arrive at a solution, require them to 
make some simplifications, and require them to make detailed visual representations to understand the problem. Furthermore, we hypothesize that the problem must also be complex enough (e.g., not simply an exercise) that the students need to do some planning to reach a solution; this typically requires that the problem comprises multiple steps, each of which invokes different concepts or pieces of information. More importantly, the problem must require students to make the decision to decompose the solution and plan out their strategy. However, if the complexity or required content knowledge of the problem requires use of a predictive framework that is beyond the students' level of mastery, they will be incapable of making the decisions required by the template, and it becomes irrelevant [39]. Students are unable to frame such problems, and thus make little headway on their solutions.

In investigating our initial research questions, we discovered where student difficulties in problem solving lie in relation to the expert problem solving decisions identified by Price et al. [23]. Indeed, both the interviews and the analysis of $41 \mathrm{E}$ exam solutions point to two key difficulties: selecting and adapting predictive frameworks to fit the problem at hand and deciding upon a detailed solution plan. Failure to effectively make both of these decisions reflect weaknesses in students' predictive frameworks. Their predictive frameworks lack either some important key features (e.g., the energy dissipated by a frictional force) or some of the relationships between those features (e.g., how to describe the acceleration of an extended object before it leaves the ground or estimate required values). This prevents them from being able to formulate a detailed solution plan.

An important area of future research is how we can effectively teach our students these expert predictive frameworks. Indeed, some preliminary investigations suggest that standard instructional practices and curriculum are not teaching these frameworks and their application to students in chemical engineering [40] or medicine [39], and our results here show that the same is true in physics courses at Stanford. Because predictive frameworks are mental models of problems' key features and the relationships between them, we suggest that instruction in problem solving should focus on having students identify the key features of given problems, and then practice manipulating the relationships between relevant variables. For example, if one were to use the truck problem as an instructional tool, we would suggest first having students work in groups to identify the most important features of the scenario-what physical quantities will be of interest, what processes are taking place, etc. Context-rich problems or synthesis problems are good problems to practice this with, as they require students to think more carefully about the features of the problem than typical textbook problems [41]. This will help them identify relevant concepts and construct a good visual representation of the problem. Since planning is a notable weakness in students' solutions, we suggest using contrasting cases to help students learn what the elements of a good solution plan are [42]. Students can be given two plans to solve a problem and then critique them so that they realize what the elements of a good plan are. To help students exercise their predictive frameworks, we recommend an emphasis on having students explore their solutions once they have reached them. Beyond checking units, they should think about relationships between variables and whether they make sense-e.g., if the mass of the truck doubles, does the distance it coasts up the hill change? Warren's work on teaching evaluation strategies suggests this may be a good approach [33].

The literature on problem solving suggests many other strategies that could work to help students learn good problem solving. For example, students could be given good worked examples of how the template is used in class, so that they have references for what good problem solving looks like $[30,43]$. However, more work is certainly needed to identify good strategies for teaching students how to solve complex, real-world physics problems. As with research on expert and novice differences in problem solving, most studies of how to teach problem solving have focused on textbook problems [44]. Authentic problems contain other elements, such as irrelevant or missing information, that make certain suggested strategies; e.g., identifying relevant physics concepts, identifying and making assumptions, and developing abstract representations; more difficult for students. Yet, these types of unstructured problems are the ones that students will most often encounter in their careers, so it is essential that we find ways to develop students' expertise in solving authentic problems.

\section{ACKNOWLEDGMENTS}

This work was determined exempt from IRB review under Stanford University protocol IRB-48006. The authors thank the instructors of Physics 41 and $41 \mathrm{E}$ for providing us with student course data and exam solutions, the interview participants for their time and cooperation, and Argenta Price for her thoughts on the coding of the student interviews. This work is partially supported by the Howard Hughes Medical Institute Grant No. 1213289-100-UALZC. 


\section{APPENDIX: RUBRICS}

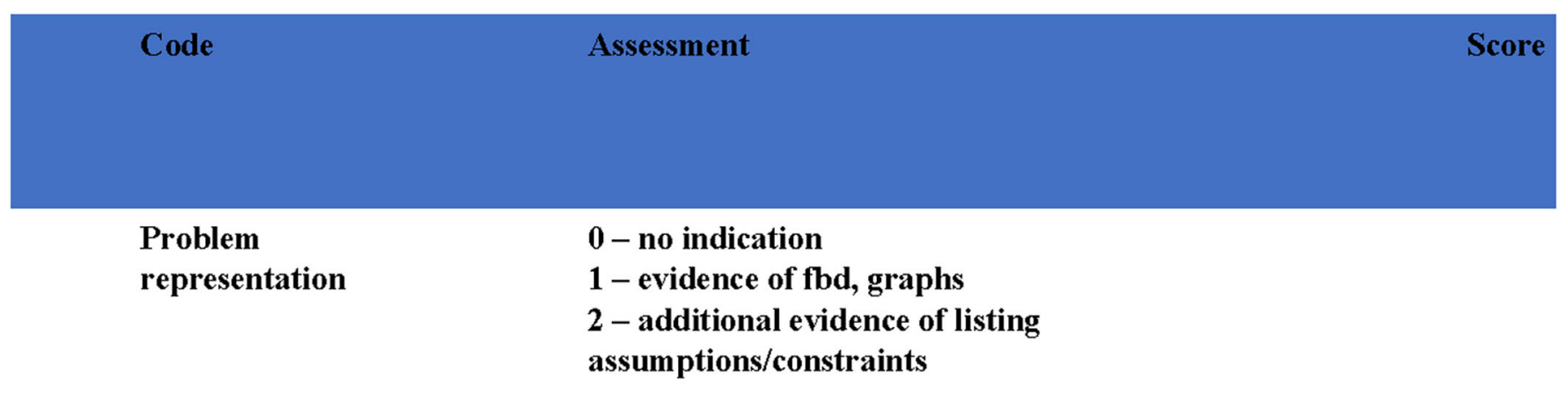

Problem

decomposition

Data collection / planning

Reflection on knowledge

Solution verification
0 - no indication

1 - evidence of implicit decomposition

2 - evidence of explicit (verbal) decomposition

0 - no indication

1 - evidence of recognizing / recording given

information

2 - evidence of incorporating all given information in final solution

0 - no indication

1 - evidence of listing any equations

2 - evidence of listing all correct relevant equations

3 - evidence of explicitly describing concepts related to equations

$0-$ no indication

1 - evidence of attempted yet failed verification

2 - evidence of attempted and successful verifcation

FIG. 7. Rubric for Atwood machine problem. 


\section{Truck Problem}

A truck of mass $\mathrm{M}$ is driving down a steep mountain road at a speed $\mathrm{V}_{0}$, and suddenly its brakes fail. It coasts without friction a distance d down the slope before getting to a runaway truck ramp. How fast is it going when it gets to the ramp (the bottom of the slope)?

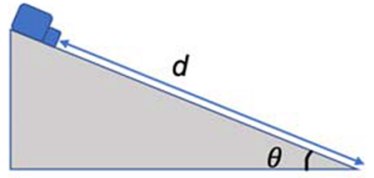

Make a Visual Representation of the Energy Transformations Involved (3 points):

+1 point:

- Mentions transfomation frompotential to kinetic energy/Conservation of Energy +1 point:

- Diagram complete- shows block with Vo moving down ramp, labels $d, 8$, height (h) +1 point:

- Diagram drawn

0 points:

- No attempt

Relevant Concepts (2 points):

+1 point:

- Correctly mentions that object at height (h) has gravitational potential energy Mgh

+1 point:

- Correctly mertions final kinetic energy $=1 / 2 \mathrm{Mv}^{2}$

0 points:

- No attempt/ Totally incorrect

Assumptions and Simplifications (1 point):

+1 point:

- Assumes that the angle $(\theta)$ is constant along the slope

Information Needed (2 points):

+.5 points:

- Recognizes that mass of the truck is not necessary as it will cancel out
+.5 points:

- Mentions using the length of the mountain (d) to find $\mathrm{h}$

+.5 points:

- Mentions the necessity of using the ange $(\theta)$ to find $h$

+.5 points:

- Mentions using $V_{0}$ to find initial kinetic energy

0 points:

- None of the above included

Solution Plan (3 points):

+1 point:

- Adds sufficient detail/ equations to support the reasoning behind the planring steps listed below

- Find $h$ of the ramp using $h=d \sin \theta$

+1 point:

- Contains correct steps/ideas

- Mentions:

- Change from potential and kinetic to just kinetic energy as block moves down ramp

- Need to solve for height (h) of the ramp

+1 point:

- Partly complete, but may lack some steps

0 points:

- No mention of energy

Execution (3 points):

+1 point

- $\quad$ Set $E_{1}=E_{1}$ equal

+.5 points:

- Correct expression for initial PE: mgh

+.5 points:

- Correct expression for initial and final $\mathrm{KE}: 1 / 2 \mathrm{mv} \mathrm{v}^{2}$

+.5 points:

- Correct trig for $h$ calculation ( $h=d \sin \theta$ )

+.5 points:

- Correct answer for $V_{D}$

0 points:

- Totally incorrect/ no attempt

FIG. 8. Rubric for truck problem, part 1. 


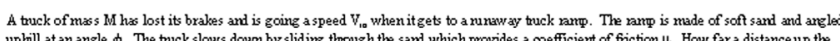
uphill at an angle $\phi$. The truck slows down by sliding though the sand which provides a coefficiert of friction $\mu$. How far a distance up the

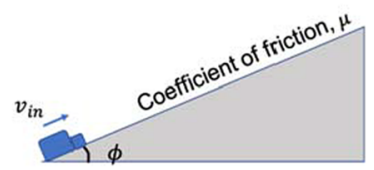

Malea Virval Kepresentation of the Energy I ransformations Irrobed (3 points):

Rekvant Concept (2point):

+1 point:

- Mentions loss of energy due to friction

+1 point:

- Mentions conservation of energy/transformation from kinetic to potential energy +.5 points:

- Diagram complete-- shows block with $V_{\mathbf{k}}$ moving up ramp, friction opposing motion of block (force with coefficient $\mu$ pointing down ramp) labels $\mathrm{d}$, $\Phi$, height (h) +.5 points:

- DiagramDrawn

0 points:

- No attempt

+.5 point:

- Conectly mentions work dore by force $=$ /F Dds

+5 point:

+.5 poirts: Comectly mextions Friction $=\mu \mathrm{N}$

+.5 poirts: Comectly mentions that object at height (h) has gravitational potertial energy Mgh

- Comeetly mextions iritial kiretic enezy $=4, M^{2} v^{2}$

0 poirts:

- No attempt' Totally incorrect

Assumptions and Sinplifications (1 poind):

+.5 points:

+5 Assumes that the ande ( $\$$ ) is corstart along the slope

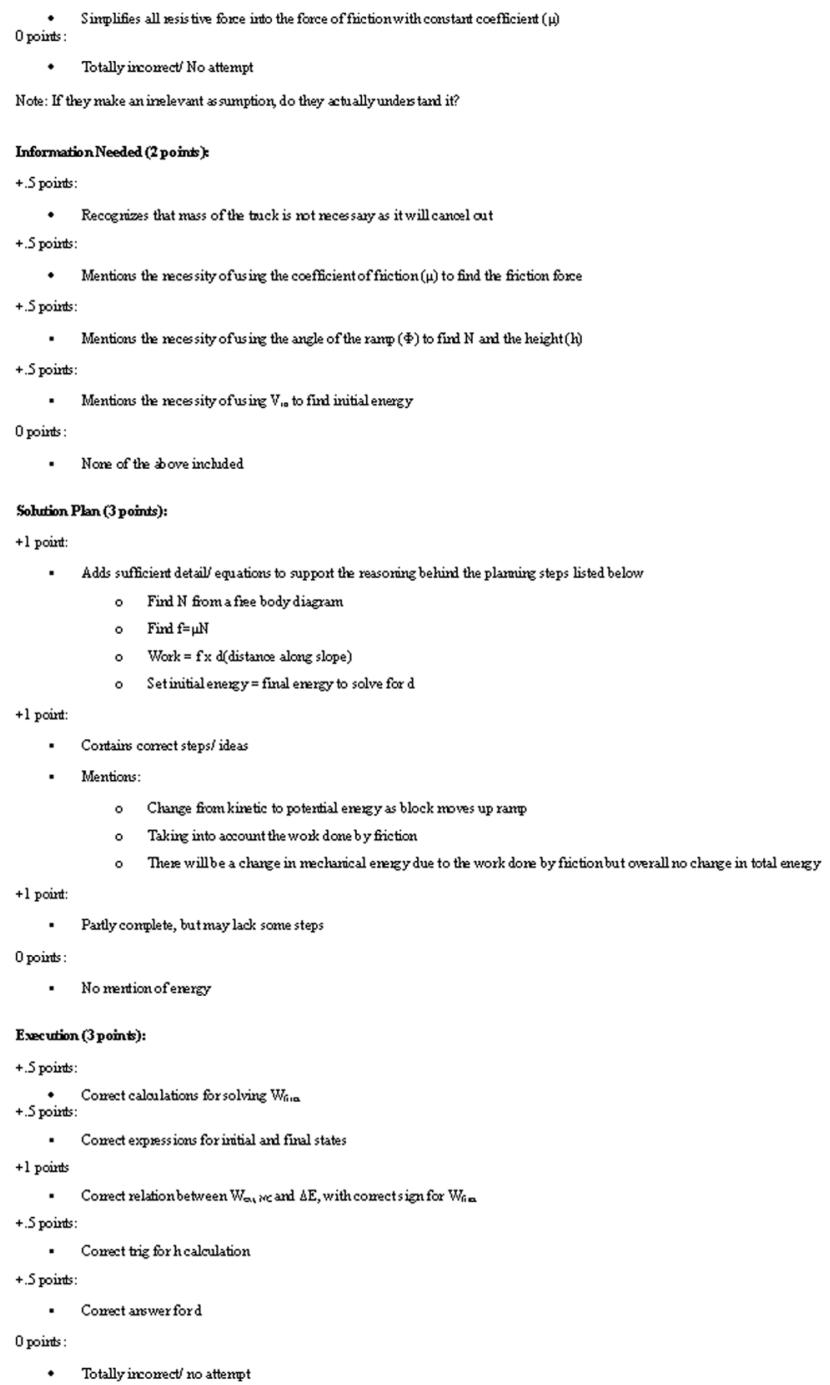

FIG. 9. Rubric for truck problem, part 2. 


\section{Horsepower Problem:}

Engine power is sometimes expressed in terms of "horsepower." One horsepower was defined by James Watt, who observed that a horse could turn a particular mill wheel with a radius of $3.7 \mathrm{~m}$ at a constant rate of 144 times per hour by exerting a force of $81.6 \mathrm{~kg}$ tangentially to the wheel. What is the conversion for horsepower to kilowatts?

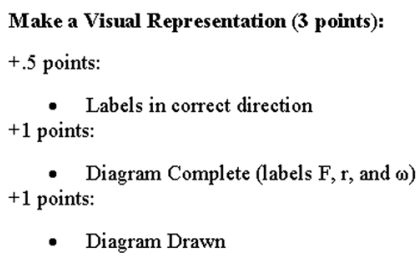

- Assuming that the force is always tangential (angle stays the same)

Information Needed ( 2 points):

+.5 points:

- Need force (F) that the horse can pull

+.5 points:

- Need angular velocity $(\omega)$ that the wheel is moving +.5 points:

- Need radius $(\mathrm{R})$ of the wheel

+.5 points:

- All correct units

Solution Plan (3 points):
+1 point:

- Gives equations/specific examples to support steps, including:
- $\quad \mathrm{v}=\mathrm{R} \omega$
- $\mathrm{P}=\mathrm{E} / \mathrm{t}$
- $\mathrm{P}=\mathrm{Wt}$
- $\mathrm{W}=\mathrm{Fd} \cos \theta--\mathrm{d}=\mathrm{distance}$ travelled $=\mathrm{V}^{*} \mathrm{t}$

+1 point:

- Gives all the correct steps

- Mentions converting $\omega$ into $\mathrm{rad} / \mathrm{s}$

- Mentions solving for $\mathrm{v}$ by using $\omega$ and $\mathrm{R}$

- Mentions solving for Power using Force and velocity in $\mathrm{kW}$ +1 point:

- Solution plan there, but missing certain steps

Execution (3 points):

+.5 points:

- Correctly converts $\omega$ into $\mathrm{rad} / \mathrm{s}$

+.5 points:

- Correctly finds $v$ from $R$ and $\omega$

+.5 points:

- Correct conversion $\mathrm{F}$ into $\mathrm{N}$ (multiply by g)

+1 points:

- Correct and applicable equation for power

+.5 points:

- Correct answer in kW $(.744 \mathrm{~kW})$

FIG. 10. Rubric for horsepower problem. 


\section{Homework, Week 2}

A common exercise to strengthen chest, arm, and shoulder muscles is the push-up. Many variations on this exercise exist to increase or decrease the difficulty, or to target specific

muscles. One such modified push-up is done with the knees in contact with the floor. What

is the difference in the force required between a regular push-up and a modified push-up?

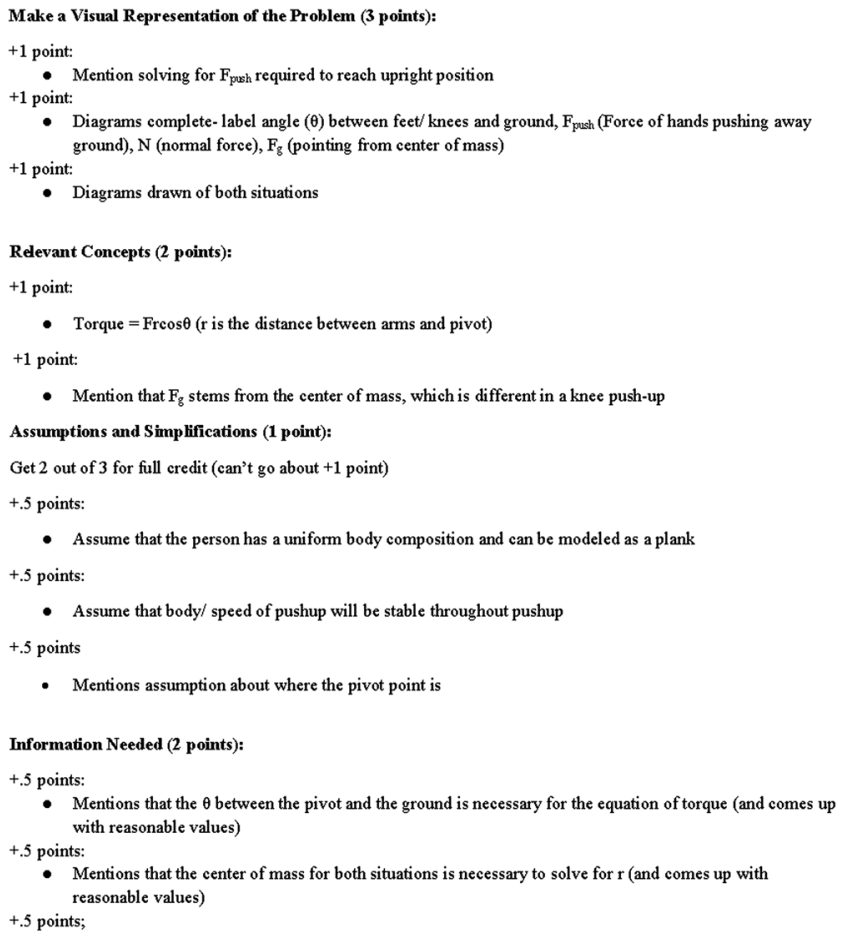

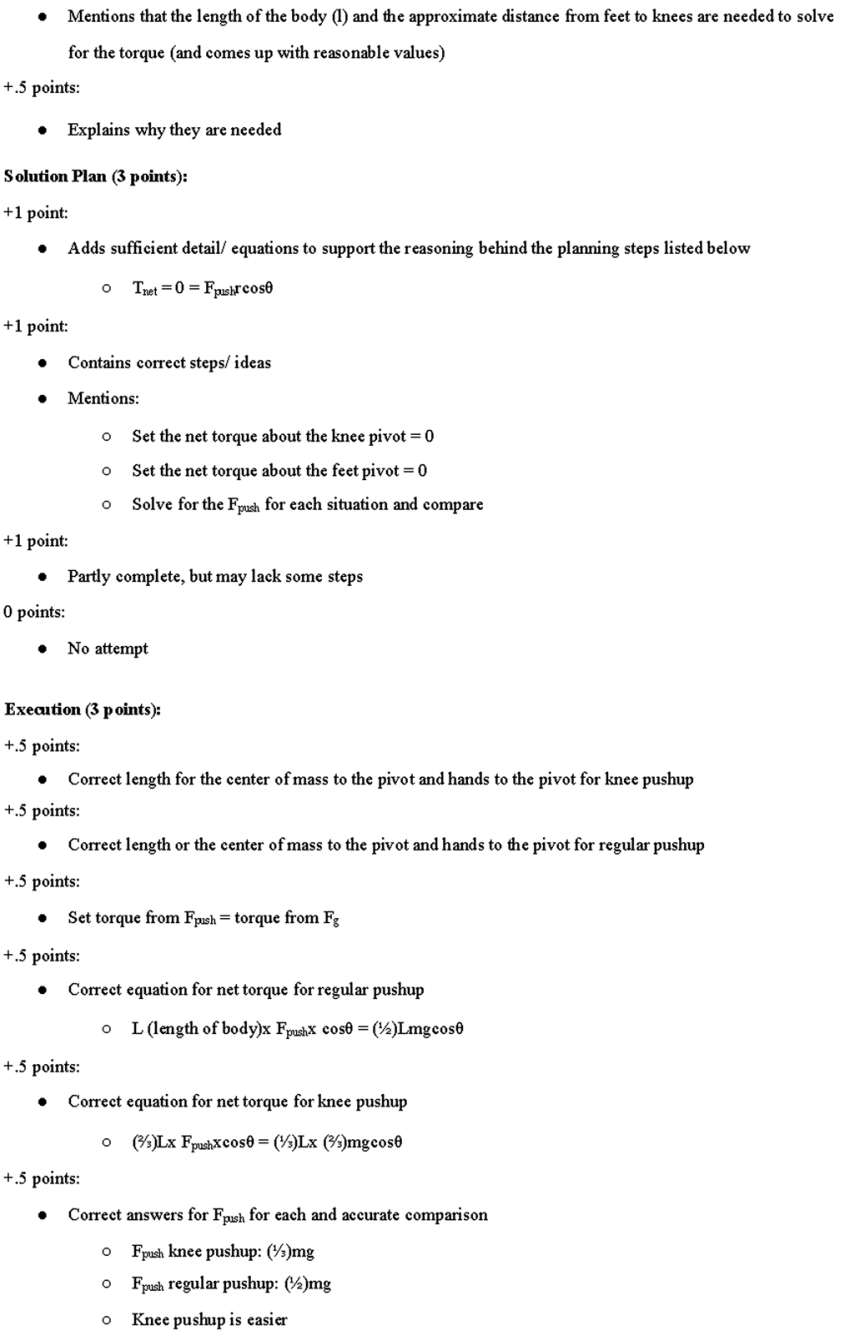

FIG. 11. Rubric for homework, week 2 . 
Homework, Week 8

A popular amusement park ride is called The Rotor. You climb down into a cylindrical metal cylinder with a radius of 5 meters and stand a gainst the wall. The attendant starts the ride and the cylinder starts to rotate with the assistance of $33 \mathrm{~kW}$ motor ( $1320 \mathrm{Nm}$ torque). After a certain amount of time, the floor drops out, but you stay stuck to the wall If you weigh $70 \mathrm{~kg}$ and the coefficient of firction between your clothes and the wall is 0.2 . How long should the operator wait before dropping the floor?

Make a Visual Representation of the Problem ( 3 points):

+.5 points:

- Mentions that the whole rotor (coordinate frame) is accelerating during thisrife +1.5 points:

- Diagram complete- label $\mathrm{f}_{\mathrm{f}}$ pointing up, $\mathrm{F}_{\mathrm{g}}$ pointing down, $\mathrm{N}$ pointing toward the center of the cylinder, $\tau$ pointing either $\mathrm{CW}$ or $\mathrm{CCW}, \mathrm{a}=\mathrm{v}^{2} / \mathrm{r}$ pointing to center of circle +1 point:

- Diagram included

Relevant Concepts (2 points):

Method 1 (Rotational Kinematics):

+.5 points

Includes:

- Forces in y-dir (up/down) must add to 0 to keep you from falling $\left(\mathrm{f}_{\mathrm{s}}=\mathrm{mg}\right)$ - $\mathrm{f}_{\mathrm{s}} \leq \mu \mathrm{N}$

+.5 points

Newton'sLaw. F=m

points:

- Angular Newton's Law. $\tau=l \alpha$

+.5 points

- Includes.

- I(Person as a point $)=m r^{2}$

- angular acceleration* radius=acceleration or with velocity

Method 2 (Rotational Energy)

+1 point:

- Forces in $\mathrm{y}-$ dir (up/down) must add to 0 to keep you from falling $(\mathrm{f}=\mathrm{s} \mathrm{m})$

- $\mathrm{f}_{\mathrm{s}} \leq \mu \mathrm{N}$

+1 point

- $P=\Delta E / t$

- $\Sigma E=E_{\text {traselahiona }}+E_{\text {rotation }}$

Assumptions and Simplifications (1 point)

- Use rotational kinetic energy and the relationship between power and energy to solve for the time

+1 point

- Partly complete, but may lack some steps

0 points

- No attempt

Exec ution (3 points)

Method\#?:

+.5 points:

- Correct relationships between $\mathrm{f}_{\mathrm{s}}$ and $\mathrm{N}$

- Correct relationship between $\mathrm{f}_{\mathrm{s}}$ and $\mathrm{F}_{\mathrm{g}}$ in order for you not to fall

+5 points:

- Set $\mathrm{a}_{\mathrm{e}} \mathrm{m}=\mathrm{N}$ and solve for $\mathrm{y}$

point:

- Correct equation for torque

- Correct rotaticnal kinematics to solve for $w$ in terms of

5 points:

- Mentions that $\omega=v / /$

Plug in equation far $z$ and equation for $\omega($ into equation above) to solve for 1 - $\tau t / I=(r g / \mu) / \mathrm{r}$ or another form $(\mathrm{t}=\gamma g / \mu * \mathrm{~V}(\mathrm{r} \tau))$ or $\mathrm{t} \tau / \mathrm{mr}=r g / \mu$

+.5 points:

- Correct answer for $t(t=4.15 \mathrm{~s})$

Method \#2:

+5 points:

- Correct relationships between $\mathrm{f}$, and $\mathrm{N}$

- Correct relationship between $f_{s}$ and $F_{g}$ in order for you not to fall

+.5 points:

- Set $\mathrm{a}_{\mathrm{c}}=\mathrm{N}$ and solve for $\mathrm{V}$

- Appropriate manipulations from $\mathrm{K}_{\mathrm{tras}}$ to $\mathrm{K}_{\mathrm{se}}$ of Accurately detemines that $\mathrm{K}_{\mathrm{sur}}-1 /(1 / 2)\left[\omega^{2}\right.$

+.5 points:

- Correctly modifies $v$ from previous step to $\omega$

.5 points:

- Accurately determines that $P=\Delta E / t$ and plugs in $\mathrm{K}_{\text {rot for }} \Delta E$

+.5 points

- Correct answer for $t(t=6.5 \mathrm{~s})$
+.5 points

- Simplifying a person to a point with a moment of inertia $(\mathrm{I})=\mathrm{mr}^{2}$

.5 points:

- Assuming constant power from the motor

Information Needed (2 points):

+.5 point

- Coefficient of static friction $(\mu=2)$ to find $\mathrm{f}_{5}$

- Radius of the mor 5

5 points:

Power or torque of the rotor engine $(\mathrm{P}=33 \mathrm{~kW} z=1320 \mathrm{Nm})$

- Explains why we need these

Solution Plan (3 points):

Method \#?:
+1 point:

- Adds sufficient detail/ equations to support the reasoning behind the planring steps listed below $\circ \quad \tau=I \alpha$
$\circ \omega=\alpha t$

- Convert to transiational kinematics and solve for $t$

- $\mathrm{f}_{-}-\mathrm{mg}$ in order for person not to fall

+1 point:

Centripetal acceleration

- Contains correct steps/ideas

- Mentions:

- Use motor torque and assumed I of the person to solve for the angular acceleration of the system - Centripetal acceleration provided by $\mathrm{N}$

+1 point:

- Partly complete, but may lack some steps

0 points:

- No attemp

Method\#2:

+1 point:

- Adds sufficient detail/ equations to support the reasoning behind the planring steps listed below

$\therefore \mathrm{K}_{\mathrm{rot}}=\mathrm{=} / 2 \mathrm{I} \omega^{2}$

$\omega=v / r$

t $r=\mathrm{mg}$ in order for person not to fall

$\therefore$ Centripetal acceleration $=v^{2} / S$

+1 point

- Contains correct steps/ideas

- Centripetal acceleration provided by $\mathrm{N}$

FIG. 12. Rubric for homework, week 8 . 
[1] ABET Engineering Accreditation Commission. ABET criteria for accrediting engineering programs, (2000). Retrieved from https:/www.abet.org/accreditation/ accreditation-criteria/.

[2] H. J. Passow and C. H. Passow, What competencies should undergraduate engineering programs emphasize? A systematic review, J. Eng. Educ. 106, 475 (2017).

[3] S. Sheppard, A. Colby, K. Macatangay, and W. Sullivan, What is engineering practice?, Int. J. Eng. Educ. 22, 429 (2007).

[4] H. Passow, Which ABET competencies do engineering graduates find most important in their work, J. Eng. Educ. 101, 95 (2012).

[5] J. Larkin, J. McDermott, D. P. Simon, and H. A. Simon, Expert and novice performance in solving phyiscs problems, Science 208, 1335 (1980).

[6] M. T. H. Chi, P. J. Feltovich, and R. Glaser, Categorization and representation of physics problems by experts and novices, Cogn. Sci. 5, 121 (1981).

[7] J. I. Heller and F. Reif, Prescribing effective human problem-solving processes: Problem description in physics, Cognit. Instr. 1, 177 (1984).

[8] P. Heller, R. Keith, and S. Anderson, Teaching problem solving through cooperative grouping. part 1: Group versus individual problem solving, Am. J. Phys. 60, 627 (1992).

[9] P. Heller and M. Hollabaugh, Teaching problem solving through cooperative grouping. Part 2: Designing problems and structuring groups, Am. J. Phys. 60, 637 (1992).

[10] W. K. Adams and C.E. Wieman, Analyzing the many skills involved in solving complex physics problems, Am. J. Phys. 83, 459 (2015).

[11] C. Wieman, Comparative cognitive task analyses of experimental science and instructional laboratory courses, Phys. Teach. 53, 349 (2015).

[12] M. P. Čančula, G. Planinšič, and E. Etkina, Analyzing patterns in experts' approaches to solving experimental problems, Am. J. Phys. 83, 366 (2015).

[13] L. Hsu, E. Brewe, T. M. Foster, and K. A. Harper, Resource letter RPS-1: Research in problem solving. Am. J. Phys. 72, 1147 (2004).

[14] S. Salehi and C. E. Wieman, A problem-solving framework: Characterizing actions and decisions involved in solving a complex problem (to be published).

[15] A. Van Heuvelen, Mechanics Active Learning Problem Sheets (Hayden-MacNeil, Plymouth, MI, 1996).

[16] K. Heller and P. J. Heller, Competent Problem SolverCalculus Version (McGraw-Hill, New York, 2000).

[17] H. D. Young and R. A. Freedman, University Physics with Modern Physics, 14th ed. (Pearson, Boston, 2015).

[18] R. D. Knight, Physics for Scientists and Engineers: A Strategic Approach, 4th ed. (Pearson Boston, 2017).

[19] H. A. Schoenfeld, Mathematical Problem Solving (Academic Press New York, 1985).

[20] M. S. Sabella and E. F. Redish, Knowledge organization and activation in physics problem solving, Am. J. Phys. 75, 1017 (2007).

[21] D. R. White, R. Badeau, A. F. Heckler, and L. Ding, Bottlenecks In Solving Synthesis Problems, in Proceedings of the 2014 Physics Education Research Conference,
Minneapolis, MN, edited by P. V. Engelhardt, A. D. Churukian, and D. L. Jones (AIP, New York, 2014).

[22] N. Shin, D. H. Jonassen, and S. McGee, Predictors of well-structured and ill-structured problem solving in an astronomy simulation, J. Res. Sci. Teach. 40, 6 (2003).

[23] A. M. Price, C. Kim, E. Burkholder, M. Flynn, A. Fritz, and C.E. Wieman, Identifying expert problem solving decisions (to be published).

[24] A. Collins, J. S. Brown, and A. Holum, Cognitive apprenticeship: Making thinking visible, Am. Educat. 15, 6 (1991).

[25] A. Van Heuvelen, Learning to think like a physicist: A review of research-based strategies, Am. J. Phys. 59, 891 (1991).

[26] A. Van Heuvelen, Overview, case study physics, Am. J. Phys. 59, 898 (1991).

[27] N. Holmes, B. Keep, and C. Wieman, Phys. Rev. Phys. Educ. Res. 16, 010109 (2020).

[28] A. F. Heckler, Some consequences of prompting novice physics students to construct force diagrams, Int. J. Sci. Educ. 32, 1829 (2010).

[29] K. A. Ericsson, R. R. Hoffman, A. Kozbelt, and A. M. Williams, The Cambridge Handbook of Expertise and Expert Performance (Cambridge University Press, Cambridge, England, 2018).

[30] W. J. Leonard, R. J. Dufresne, and J. P. Mestre, Using qualitative problem-solving strategies to highlight the role of conceptual knowledge in solving problems, Am. J. Phys. 64, 1495 (1996).

[31] R. J. Dufresne, W. J. Gerace, P. T. Hardiman, and J. P. Mestre, Constraining novices to perform expertlike problem analyses: Effects on schema acquisition, J. Learn. Sci. 2, 307 (1992).

[32] J. P. Mestre, R. J. Dufresne, W. J. Gerace, P. T. Hardiman, and J.S. Touger, Promoting skilled problem-solving behavior among beginning physics students, J. Res. Sci. Teach. 30, 303 (1993).

[33] A. R. Warren, Impact of teaching students to use evaluation strategies, Phys. Rev. ST Phys. Educ. Res. 6, 020103 (2010).

[34] P. B. Kohl and N. D. Finkelstein, Patterns of multiple representation use by experts and novices during physics problem solving, Phys. Rev. ST Phys. Educ. Res. 4, 010111 (2008).

[35] J. L. Docktor, J. Dornfeld, E. Frodermann, K. Heller, L. Hsu, K. A. Jackson, A. Mason, Q. X. Ryan, and J. Yang, Assessing student written problem solutions: A problemsolving rubric with application to introductory physics, Phys. Rev. Phys. Educ. Res. 12, 010130 (2016).

[36] M. M. Hull, E. Kuo, A. Gupta, and A. Elby, Problemsolving rubrics revisited: Attending to blending of informal conceptual and formal mathematical reasoning, Phys. Rev. ST Phys. Educ. Res. 9, 010105 (2013).

[37] L. C. McDermott and P. S. Shaffer, Tutorials in Introductory Physics (Prentice Hall, Upper Saddle River, NJ, 2002).

[38] C. H. Crouch and E. Mazur, Peer instruction: Ten years of experience and results, Am. J. Phys. 69, 970 (2001).

[39] C. Kim, A. M. Price, C. E. Wieman, and S. F. Chen, Assessing clinical reasoning using a framework of expert decision making (to be published). 
[40] E. W. Burkholder, A. M. Price, M. P. Flynn, and C. E. Wieman, Assessing problem solving in science and engineering programs, in Proceedings of the 2019 Physics Education Research Conference, Provo, UT, edited by Y. Cao, S. Wolf, and M. B. Bennett (AIP, New York, 2019).

[41] L. Ding, N. Reay, A. Lee, and L. Bao, Exploring the role of conceptual scaffolding in solving synthesis problems, Phys. Rev. ST Phys. Educ. Res. 7, 020109 (2011).

[42] D. L. Schwartz, J. M. Tsang, and K. P. Blair, The ABCs of How We Learn: 26 Scientifically Proven Approaches,
How they Work, and When to Use Them (W. W. Norton \& Company, New York, 2016).

[43] M. T. H. Chi, M. Bassok, M. W. Lewis, P. Reimann, and R. Glaser, Self-explanations: How students study and use examples in learning to solve problems, Cogn. Sci. 13, 145 (1989).

[44] J. P. Mestre, R. J. Dufresne, W. J. Gerace, P. T. Hardiman, and J.S. Touger, Promoting skilled problem-solving behavior among beginning physics students, J. Res. Sci. Teach. 30, 303 (1993). 